\title{
ВАОХНОВАЕННЫЙ МОРЕМ
}

Ааценко Алена Алексеевна

ИскусствовеА, Аиректор Приморской

государственной картинной галереи

(г. ВАадивосток), член ВТОО «Союз

художников России», член Ассоциации

искусствоведов России (АИС), член

межАународного совета музеев (ICOM),

Почетный консультант Художественного

музея г. Нинбо (Китай).

Россия, г. ВАадивосток.

shergil@mail.ru

\section{Аннотация}

Николай Максимович Штуккенберг принадлежит к славной плеяде художников, которые стояли у истоков приморской живописи, формировали специфику Аальневосточного пейзажа. Родился Николай Максимович в 1880 году в Петербурге. В 1885-м семья переехала в Тверь. И только в 1907 году Штуккенберг, будучи уже капитаном дальнего плавания, вернулся в родной город. С зимы того же года до 1910-го с увлечением посещал живописное отделение Императорской академии художеств в качестве вольнослушателя ${ }^{6}$. Но в 1913 году занятия были прерваны: по Аичному приглашению начальника ВАаАивостокского торгового порта капитан Штуккенберг повец медокол «Аобрыня Никитич» во ВАадивосток. С этого времени его служба, жизнь и творчество навсегда связаны с Аальним Востоком. 3Аесь Николай Штуккенберг заявиц о себе и как умелый капитан, и как художник - замечательный пейзажист, автор морских пейзажей.

КАючевые слова: искусство Аальнего Востока, маринистика, капитан-художник.

\section{Библиографическое описание Амя цитирования:}

Ааценко А.А. ВАохновленный морем // Искусство Евразии. - 2016. - № 2(3). - С. 60-68. DOI: 10.25712/ASTU.2518-7767.2016.02.005. [ЭАектронный ресурc] URL: https://readymag.com/ u50070366/575921/17/

\footnotetext{
${ }^{6}$ Согласно уставу Академии художеств 1859 года, учащиеся подразделялись на две категории бесплатных учеников и вольноприходящих, допускавшихся в классы за плату, никаких сословных ограничений при приеме студентов не вводилось. Поэтому состав учащихся Академии художеств был довольно пестрым. В своих воспоминаниях И.Е. Репин так описывал одну из академических аудиторий конца 1860-х годов: «...плечом к плечу с лохматой головой юнца в косоворотке сидел седенький генерал в погонах; дальше бородач во фраке (красавец художник с эспаньолкой!), потом студент университета, высокий морской офицер с окладистой бородой; повыше целая партия светловолосых вятичей, полная дама - тогда еще большая редкость в Академии художеств, большеглазые грузины, армяне, казачий офицер, чопорные немцы...».
} 
Посещение Академии художеств в качестве вольнослушателя несомненно сыграло важную роль в становлении Н.М. Штуккенберга как художника-пейзажиста. Творчество его формировалось в сложное Аля русского общества прелреволюционное время, которое нашло свое отражение в искусстве. Возникали многочисленные художественные течения и группы, многие из них во главу угла в творчестве ставили эксперимент. В Приморской государственной картинной галерее хранится альбом с миниатюрами Н.М. Штуккенберга, в которых проявилось влияние на художника новых тенденций. Что касается живописи, то здесь Николай Максимович оставался прямым продолжателем традиций отечественной пейзажной школы.

Наиболее яркие произведения художник написал в реалистической манере. Его изображения скромных уголков северной дальневосточной природы привлекают внимание зрителя непосреАственным восприятием натуры и особенным характером живописи. В них тот же строгий реализм, стремление к простоте, искренности и сердечности, умение найти красоту в самом простом мотиве выливаются в подиинную и убедительную трактовку природы. Его «Затопленный берег», где мелкие пастозные мазки уверенно мепят форму подтопленной земли, сопок, светлых облаков, полон тонкого миризма. Цельность изавершенность форм, гармоничность их соотношений в произведении поднимают натурный мотив Ао значительного и завершенного образа. НаслеАуя традиции отечественной пейзажной живописи в творчестве ее кучших представителей, Штуккенберг однако ни на кого не похож, и объясняется это прежде всего тем, что Аальневосточная природа не похожа на природу средней полосы России.

В первые десятилетия XX века, в годы, когда Николай Максимович начинац работать во ВАадивостоке, здесь не было полнокровной художественной жизни, Аа и теме Аальневосточной природы предстояло появиться вместе с работами таких художников, как Карл Николаевич Каль, Василий Алексеевич Баталов, Николай Максимович Штуккенберг. Многое в дальневосточной природе Аля приезжих художников было неожиданно, ново. Перед каждым из них открывался поистине необъятный мир природы Аальнего Востока. Художников того времени можно смело назвать первопроходцами в приморском искусстве, хотя каждый из них шел своим путем и «открывал» Аальневосточную природу по-своему, в соответствии со своей индивиАуаАьностью.

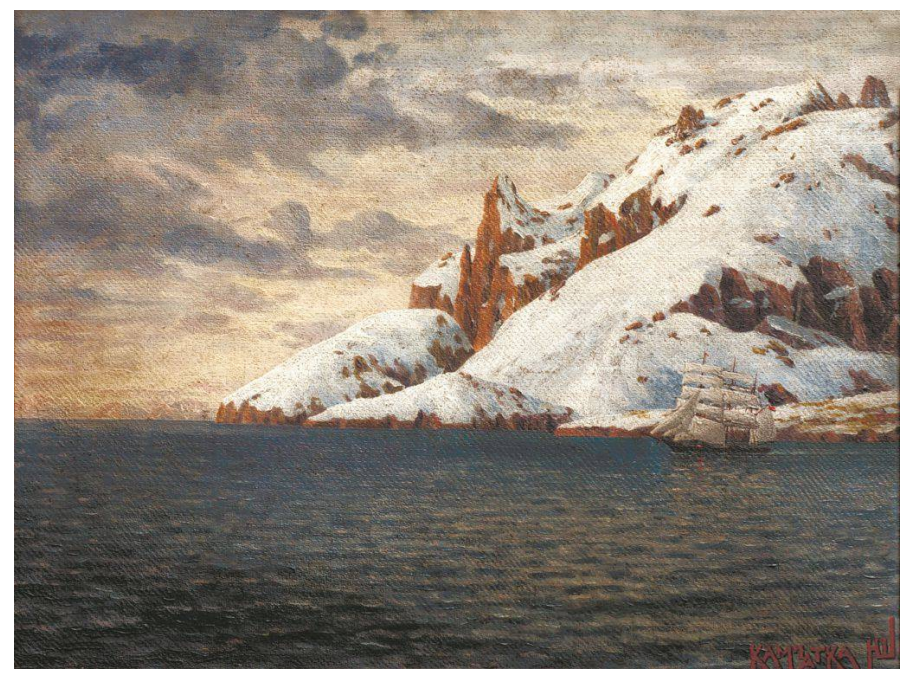

Рис. 1. Н. Штуккенберг. Побережье Камчатки близ Камбальной сопки.

Источник: bttp:/ / primkray.ru 
Нелегкая служба на флоте Штуккенберга-капитана гармонично уживалась с работой Штуккенберга-художника, она питала его творчество, открывала ему не Аоступные Аругим художникам возможности познавать удивительную красоту суровой и дикой природы. Николай Максимович Штуккенберг - один из первооткрывателей северной темы в Аальневосточном искусстве. Во время рейсов в сложных условиях короткой навигации он писал многочисленные этюды, служившие материалом Аля станковых картин, создаваемых художником по возвращении. Свежие впечатления, запечатленные в колоритных, живых этюдах, воплощались в эпические пейзажи. В некоторых из них острова, расположенные в дальней перспективе, придают Аинамику композиции, а сдержанный колорит подчеркивает магическую привлекательность северной природы. В Аругих главную роль играют световые эффекты. Строгая аскетичная красота этих земель с фантастическим мандшафтом, где привычные цвета превращаются в нереальные, Аиктует художнику выбор манеры и колорита его живописи. В северном пейзаже естественное освещение значительно отличается от Аругих, более южных областей России, оно оказывает определенное влияние на восприятие художником цвета. Зимой на фоне снега окружающие предметы выглядят более яркими, тем более на солнце. В отсутствии солнца они становятся более приглушенными, почти монохромными, и потому Ааже малонасыщенное цветовое пятно на таком фоне смотрится достаточно ярко. Какая-то особенная связь устанавливается между землей и небом, когда земля покрыта белоснежным покровом и отражает то, что Аает ей небо. Море, острова, суровые и могучие скалы, вечные мьды стали заветными темами художника.

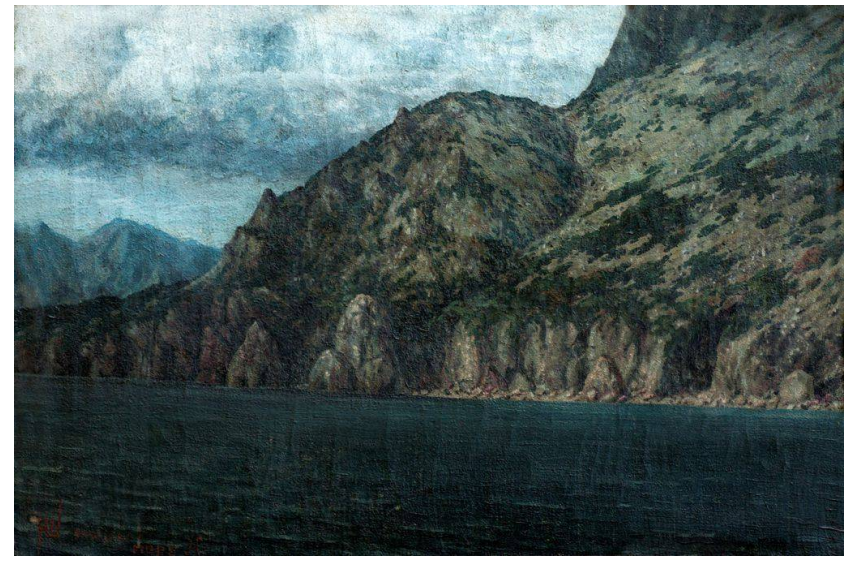

Рис. 2. Н. Штуккенберг. Близ Охотска. Источник: http://primkray.ru

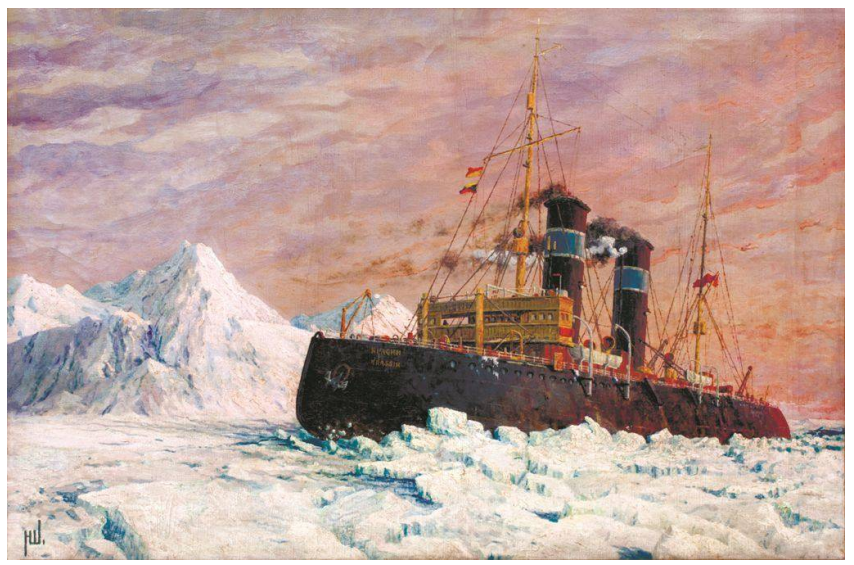

Рис. 3. Н. Штуккенберг. Аедокол Красин во Авдах. Источник: http:/ / primkray.ru

Пейзажи Николая Максимовича можно назвать Аирико-эпическими, в них никогАа не ощущается замкнутости, напротив - возникает чувство беспредельного простора. Николаю Максимовичу удавацось избегать экзотики, отражающей только внешнюю сторону природы, он старался передать главное, наиболее характерное: мощь и величие, нетронутость и первозданность Аальневосточной природы. Ее необъятность передается художником через ритмичное чередование скац, островов, глубину беспредельных синих Аалей. В изображении могучей и суровой Аальневосточной природы есть у художника характерная тема - Араматизм и героика борьбы за жизнь. Могущество северной природы часто противостоит усилиям человека, прокладывающего свои маршруты в новые, необжитые и неосвоенные места. Бескрайние морские просторы, деревья, вывернутые бурями и ураганами, изуродованные ветрами, могучие медоколы - все органически слито в еАиное целое, в одну общую ткань 
художественных образов, передающих суровую красоту Аальневосточного края и неукротимую волю человека, бросающего вызов и побеждающего стихию. Аля того чтобы передать ощущение бескрайних просторов, Н.М. Штуккенберг использует определенный прием: смещает минию горизонта вверх Аибо вниз. Большинство холстов художника ориентированы горизонтацьно, в их композиционном построении также присутствует одна или несколько Аоминирующих горизонтальных Аиний. В произведениях художника часто встречаются охристые, темно-стальные, приглушенно-зеленые оттенки («К северу от Анадыря», «Близ Охотска», «Побережье Камчатки близ Камбальной сопки», «Мыс Гамов» и другие). Интересует пейзажиста и передача различных оттенков белого, о чем свидетельствуют его работы «Вилючинская сопка», «Аедокол «Красин» во мьдах», «Морской пейзаж», «Корабль во мьдах». Тяжелые глыбы мьда сгрудились на первом плане в картине

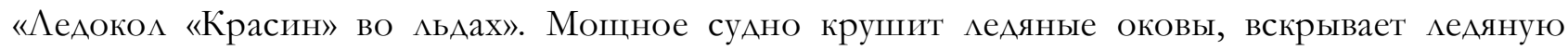
твердь, расчищая путь каравану судов, которые с нетерпением жаут северяне. Свободные и Аегкие Авижения кисти подчеркивают густоту бегущих в широком небе облаков. Плотные

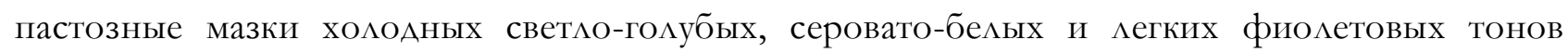

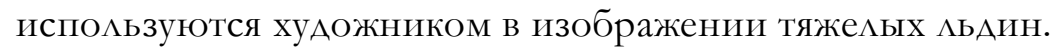

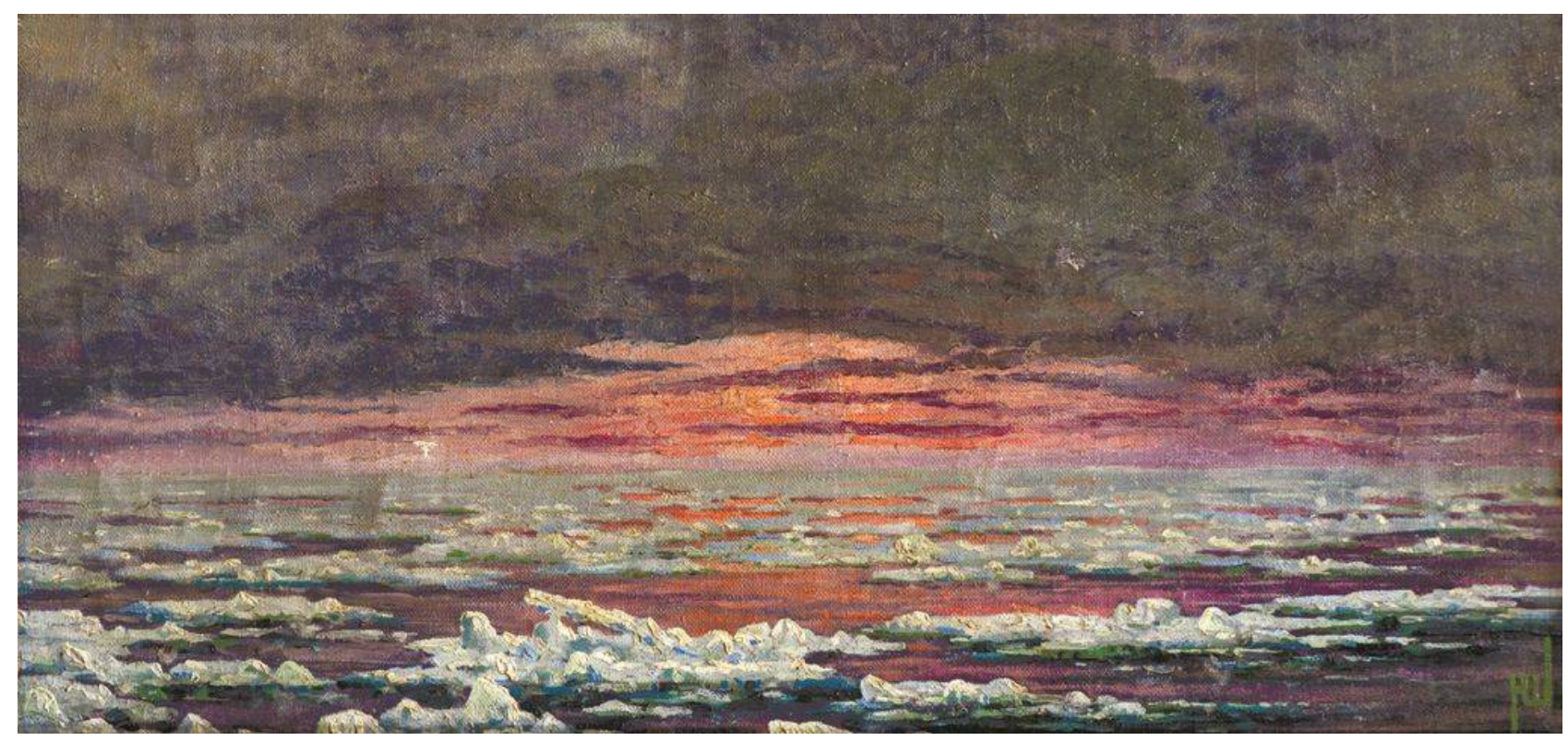

Рис. 4. Н. ШІтуккенберг. Закат. Источник: http://primkray.ru

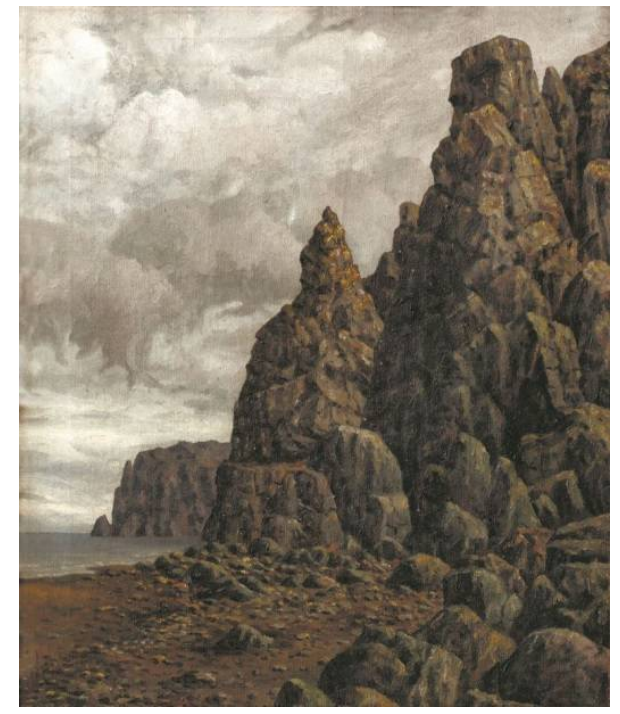

Рис. 5. Н. Штуккенберг. К северу от Анадиря. Источник:

bttp://primkray.ru 
Не только станковые произведения, но и этюды Штуккенберга часто носят эпический характер, воспринимаются как вполне завершенные произведения. Этому способствует широкое обобщенное видение, продуманность композиции, твердый и сильный рисунок, живопись плотная, материальная, построенная на глубоких, строгих и слержанных тонах. Хорошо в работах художника передан морской воздух. Аля передачи особенной свежести и прозрачности его художник использует живопись, сплавленную единством света и цвета, построенную на холодных голубых и серых тонах в контрасте с четким рисунком и темными красочными пятнами.

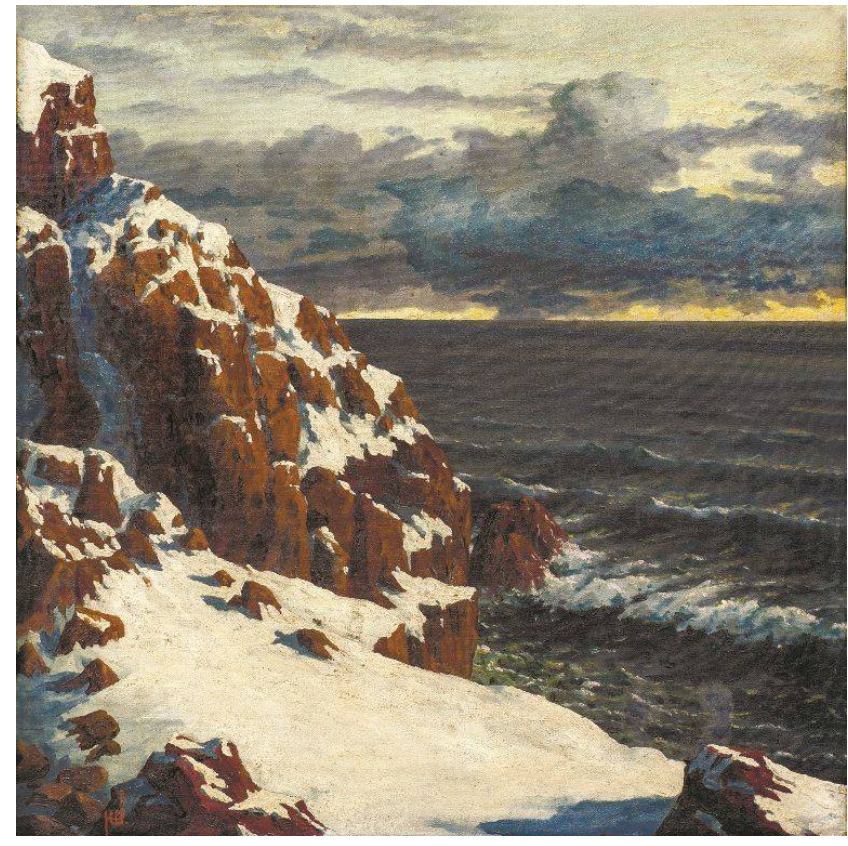

Рис. б. Н. Штуккенберг. Остров Желтухина. Источник: bttp://primkray.ru

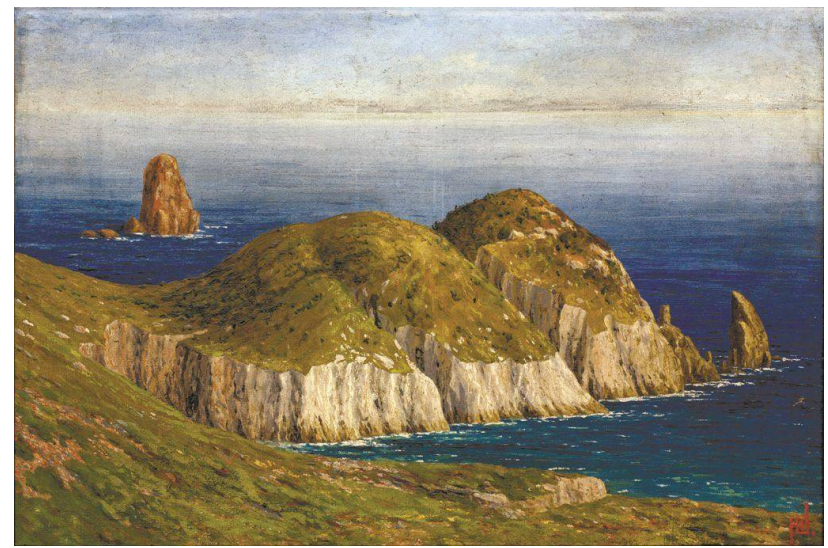

Рис. 8. Н. Штуккенберг. Скальг (Японское море). Источник: bttp://primkray.ru

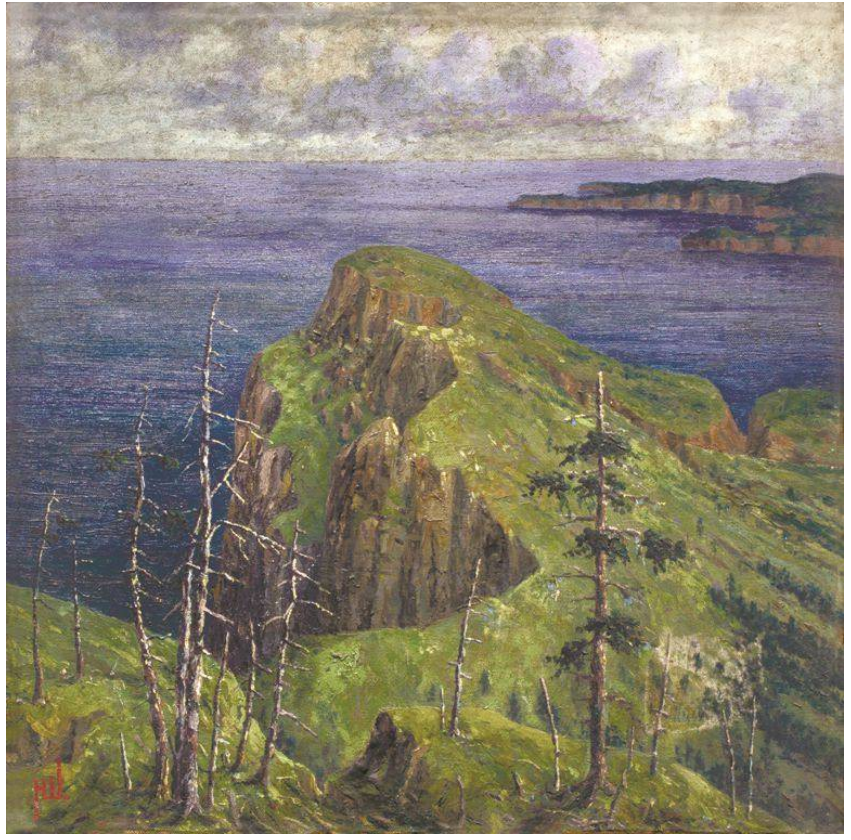

Рис. 7. Н. Штуккенберг. Мис Гамов (Японское море). Источник: bttp://primkray.ru

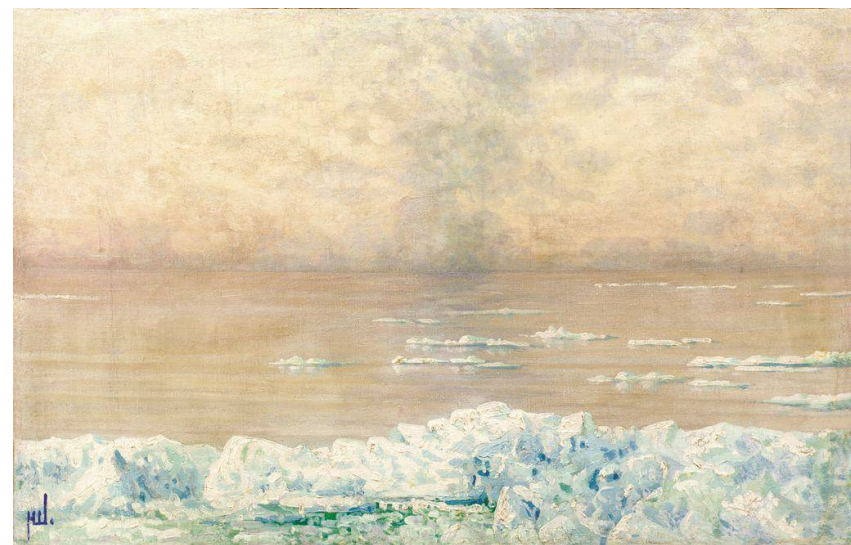

Рис. 9. Н. Штукккенберг. Морской пейзаж. Источник: bttp:/ / primkray.ru 


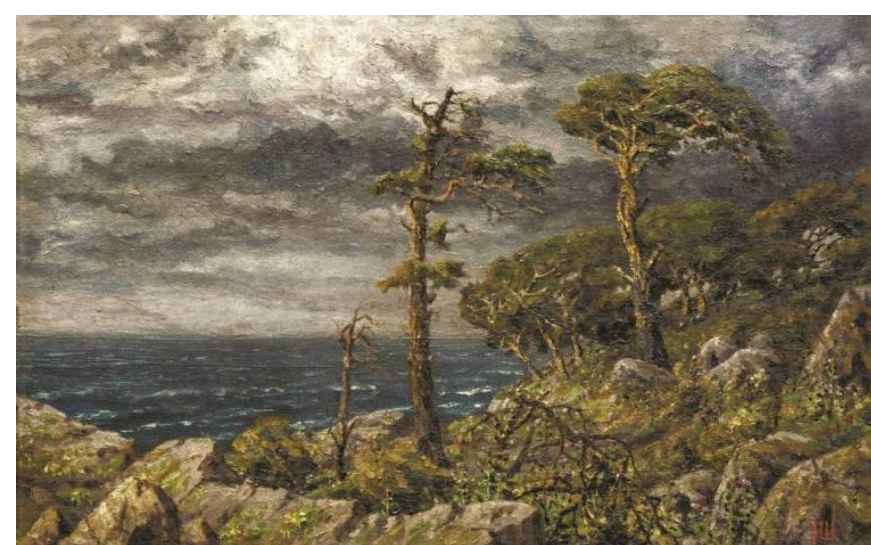

Рис. 10. Н. Шомккенберг. Мыс Гамов.

Источник: bttp://primkray.ru

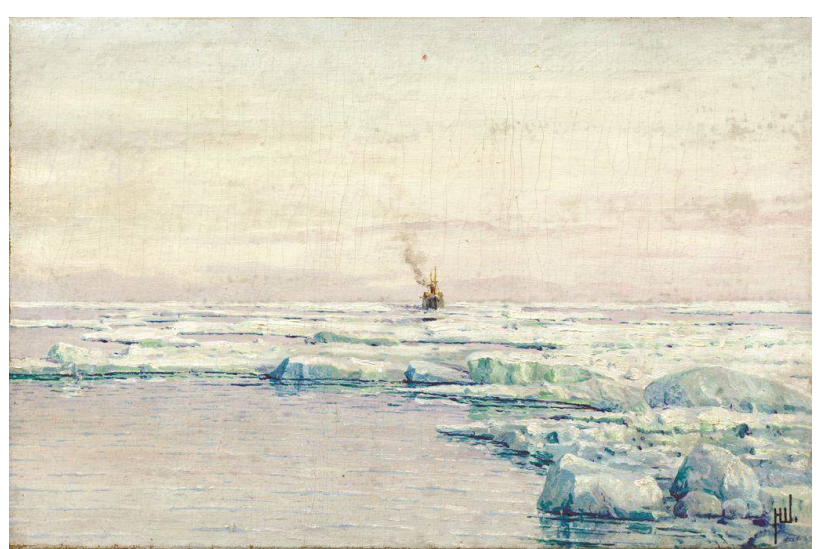

Рис. 11. Н. Штуккенберг. Корабль во льдах. Источник: bttp:/ / primkray.ru

Чувство простора и глубины открывающегося переА глазами моря, Аалеких скал Аостигается у Штуккенберга своеобразным композиционным приемом: выбором высокой точки зрения, с которой кучше всего видно то, о чем повествует художник («Мыс Гамов», «Остров Желтухина», «Скалы» и Ар.). Тем самым зритель виртуально переносится в экстремальные условия, его точка зрения предполагает нахождение на круче берега.

Особым настроением отличаются работы «Морской пейзаж» (зимний), «Корабль во АьАах». Трудно передать ощущение, которое возникает при взгляде на эти произведения. Вылержанные в изысканной гамме жемчужных, голубых, сиреневых, фиолетовых, охристожелтых тонов, которые неоднократно варьируются в работах Штуккенберга, они свидетельствуют о его живописном даровании. Произведения художника покоряют не только колористическими и композиционными Аостоинствами, но и теплым, отношением к изображаемому. Небольшие по размерам холсты передают ощущение огромного пространства, необъятного простора. Пейзажист извлекает из цветовых отношений снега и неба бесконечное разнообразие оттенков: небо как бы вбирает в себя бледные отсветы снегового наста.

Подолгу наблюдая за природой, художник улавливац тончайшие переходы ее состояний, с трогательной Аюбовью изображал скалы, покрытые снегом вулканы, водную гладь. Море его главный герой. В одних работах оно волнующееся, холодное и опасное, в Аругих спокойное и величественное. Так, в «Закате» морская гладь пламенеет, Аьдины вспыхивают, освещенные последними кучами вечернего солнца, тени сгущаются, углубляя контрасты. Но при этом изображение выглядит объективным, правдоподобным. Художник избегает применения нарочито эффектных приемов - в его живописи господствуют притушенные, матовые темно-зеленые, коричневые оттенки, преобладает спокойная гамма («Мыс Средний. Залив Америка», «Мыс Гамов», «Близ Охотска»).

Тонкий, наблюдательный художник, прекрасный знаток Аальневосточных мест, Николай Максимович Штуккенберг сумел раскрыть их природу и суровую красоту, уловить главное, самое характерное в мандшафте той или иной местности. Его пейзажи - не просто натурный материац, - это произведения, которые впервые вве и в сферу художественного отображения огромные в своей протяженности земли Аальнего Востока, запечатлели его уникальные места, стали своеобразной художественной цетописью сурового, наполненного романтикой края. 


\section{Аитература}

1. Аичаров 3. Капитан-художник: Н. М. Штуккенберг // Морской флот. - 1973. - № 8. C. 40-41.

2. Аичаров 3. Моряк-художник // Боевая вахта. - 1961. - 16 июня.

3. Кандыбо В. Его творчество питала морская жизнь: (К 100-летию со Аня рожАения Н. М. Штуккенберга - приморского художника-мариниста, капитана минейного медокола «Аобрыня Никитич» // Красное знамя. - 1980. - 30 ноября.

4. Кузнецов П. Айвазовский Приморья: (Воспоминания о художнике-моряке Штуккенберге) // Аальневосточный моряк. - 1974. - 16 июля.

5. Мясникова 3. Картины художника-моряка / К Красное знамя. - 1959. - 27 февраля.

6. Мясникова 3. Выставка картин художника-моряка Штуккенберга Н. М. // Красное знамя. - 1960. - 12 марта.

7. Плешивцева С., Воронина С. Кто отправит капитана в Аальнее плавание? (О приморском художнике Штуккенберге) // Океанские вести. - 1998. - Октябрь. - С. 36.

Статья поступима в редакцию 22.07.2016 г. 
DOI 10.25712/ASTU.2518-7767.2016.02.005

\title{
INSPIRED BY THE SEA
}

Datsenko Alena Alekseevna

Art critic, director of the Primorye State Art

Gallery (Vladivostok), member of the Union

of Artists of Russia, member of the Association

of Art Critics of Russia, member of the

International Council of Museums (ICOM),

Honorary Consultant of the Ningbo Art Museum

(China).

Russia, Vladivostok.

shergil@mail.ru

\begin{abstract}
Nikolai Maksimovich Shtukkenberg belongs to the glorious pleiad of artists who stood at the origins of Primorye's painting, formed the specificity of the Far Eastern landscape. Nikolai Maximovich was born in 1880 in St. Petersburg. In 1885 the family moved to Tver. And only in 1907 Shtukkenberg, already a captain of distant voyages, returned to his native city. Since winter of the same year until 1910, he was enthusiastically visiting the painting department of the Imperial Academy of Arts as an auditor. But in 1913 classes were interrupted: at the personal invitation of Vladivostok Commercial Port, Captain Stukkenberg led the Dobrynia Nikitich icebreaker to Vladivostok. Since that time his duty, life and work are forever connected with the Far East. Here Nikolai Shtukkenberg declared himself as a skilful captain, and as an artist - a wonderful landscape painter, the author of seascapes.
\end{abstract}

Keywords: Far East art, marine art, captain-artist, Nikolai Shtukkenberg.

\section{Bibliographic description for citation:}

Datsenko A. A. Inspired by the sea. Iskusstvo Euraziii - The Art of Eurasia, 2016, No 2(3), pp. 60-68. DOI: 10.25712/ASTU.2518-7767.2016.02.005. Available at: https://readymag.com/u50070366/575921/17/ (In Russian).

\section{References}

1. Dicharov Z. Kapitan-khudozhnik: N. M. Shtukkenberg [Captain-artist: N. M. Shtukkenberg]. Morckoi flot - The Navy fleet, 1973, No 8, pp. 40-41.

2. Dicharov Z. Moryak-khudozhnik [The seaman-artist]. Boevaya vakbta - The Combat watch, 1961, June, 16th.

3. Kandyba V. Ego tvorchestvo pitala morskaya zhizn': (K 100-letiyu so dnya rozhdeniya N. M. Shtukkenberga - primorskogo khudozhnika-marinista, kapitana lineinogo ledokola «Dobrynya Nikitich» [His work was nourished by the marine life: (To the 100th anniversary of the birth of N. M. Shtukkenberg - a seascape painter from Primorye, captain of the linear icebreaker «Dobrynia Nikitich»]. Krasnoe znamya - The Red flag, 1980, November, 30th.

4. Kuznetsov P. Aivazovskii Primor'ya: (Vospominaniya o khudoz̧nike-moryake Shtukekenberge) [Aivazovsky of Primorye: (Memories of the artist-sailor Shtukkenberg)]. Dal'nevostochnyi moryak The Far Eastern sailor, 1974, July, 16th.

5. Myasnikova Z. Kartiny khudozhnika-moryaka [Paintings of the artist-sailor]. Krasnoe znamyaThe Redflag, 1959, February, 27th. 
6. Myasnikova Z. Vystavka kartin khudozhnika-moryaka Shtukkenberga N. M. [Exhibition of paintings by sailor-artist Stukkenberg N. M.]. Krasnoe znamya - The Red flag, 1960, March, 12.

7. Pleshivtseva S., Voronina S. Kto otpravit kapitana v dal'nee plavanie? (O primorskom khudozhnike Shtukekenberge) [Who will send the captain on a long voyage? (About the artist Shtukkenberg)]. Okeanskie vesti - The Ocean News, 1998, October, p. 36.

Received: July 22, 2016. 